\title{
Renal artery stenosis in kidney transplants: assessment of the risk factors
}

\author{
This article was published in the following Dove Press journal: \\ Vascular Health and Risk Management \\ 9 August 201 I \\ Number of times this article has been viewed
}

\author{
Jalal Etemadi' \\ Khosro Rahbar ${ }^{2}$ \\ Ali Nobakht Haghighi ${ }^{2}$ \\ Nazila Bagheri ${ }^{2}$ \\ Kianoosh Falaknazi ${ }^{2}$ \\ Mohammad Reza Ardalan' \\ Kamyar Ghabili ${ }^{3}$ \\ Mohammadali M Shoja ${ }^{3}$ \\ 'Department of Nephrology, \\ Dialysis and Transplantation, Tabriz \\ University of Medical Sciences, Tabriz, \\ ${ }^{2}$ Department of Nephrology, Shaheed \\ Beheshti University of Medical \\ Sciences, Tehran, ${ }^{3}$ Tuberculosis and \\ Lung Disease Research Center, Tabriz \\ University of Medical Sciences, Tabriz, \\ Iran
}

Background: Transplant renal artery stenosis (TRAS) is an important cause of hypertension and renal allograft dysfunction occurring in kidney transplant recipients. However, conflicting predisposing risk factors for TRAS have been reported in the literature.

Objective: The aim of the present study was to assess the potential correlation between possible risk factors and TRAS in a group of living donor renal transplant recipients 1 year after the renal transplantation.

Methods: We evaluated the presence of renal artery stenosis in 16 recipients who presented with refractory hypertension and/or allograft dysfunction 1 year after renal transplantation. Screening for TRAS was made by magnetic resonance angiography and diagnosis was confirmed by conventional renal angiography. Age, gender, history of acute rejection, plasma lipid profile, serum creatinine, blood urea nitrogen, serum uric acid, calcium phosphate $\left(\mathrm{CaPO}_{4}\right)$ product, alkaline phosphatase, fasting blood sugar, hemoglobin, and albumin were compared between the TRAS and non-TRAS groups.

Results: Of 16 kidney transplant recipients, TRAS was diagnosed in three patients (two men and one woman). High levels of calcium, phosphorous, $\mathrm{CaPO}_{4}$ product, and low-density lipoprotein (LDL) cholesterol were significantly correlated with the risk of TRAS 1 year after renal transplantation $(P<0.05)$. Serum level of uric acid tended to have a significant correlation $(P=0.051)$.

Conclusion: Correlation between high $\mathrm{CaPO}_{4}$ product, LDL cholesterol, and perhaps uric acid and TRAS in living donor renal transplant recipients 1 year after renal transplantation might suggest the importance of early detection and tight control of these potential risk factors.

Keywords: transplant renal artery stenosis, atherosclerosis, calcium phosphate product, low density lipoprotein, uric acid

\section{Introduction}

Morbidity and mortality in renal transplant recipients has been attributed mainly to cardiovascular events. ${ }^{1}$ Among these events, transplant renal artery stenosis (TRAS) is the most frequent vascular complication after renal transplant. TRAS usually occurs between 3 months and 2 years after renal transplant with an incidence of $1 \%$ to $23 \% .^{2-5}$ The clinical features of TRAS include refractory hypertension, new-onset hypertension, allograft dysfunction, and presence of bruit over the graft. ${ }^{2}$ Although TRAS usually arises close to the surgical anastomosis, pre- or post-anastomotic stenosis may also occur. ${ }^{5}$ Different locations and timings of disease onset may reflect particular etiologies. ${ }^{5}$ An anastomotic stenosis is commonly related to trauma to the donor or recipient vessels during surgical manipulation and usually arises early after transplantation. ${ }^{2}$
Correspondence: Kamyar Ghabili Tabriz University of Medical Sciences, Tuberculosis and Lung Disease Research Center, Tabriz, Iran $\mathrm{Tel}+989144106136$ Fax +984113361120 Email kghabili@gmail.com 
In contrast, conflicting results have been reported about the predisposing risk factors for TRAS occurring late after transplantation (after 3 months). ${ }^{6}$ The factors potentially giving rise to TRAS include graft rejection, atherosclerotic factors, ${ }^{7,8}$ cytomegalovirus infection, ${ }^{4,6,8}$ delayed graft function, ${ }^{6}$ and long, cold ischemia time in recipients of cadaveric grafts. ${ }^{3}$ The aim of this study was to investigate the possible risk factors for TRAS among a group of renal transplant recipients who presented with refractory hypertension and/or allograft dysfunction 1 year after their transplants.

\section{Materials and methods}

In this study, we evaluated the presence of renal artery stenosis in a group of living, unrelated, donor renal transplant recipients who presented with refractory hypertension and/or allograft dysfunction 1 year after renal transplantation between December 2006 and December 2007. The ethics committee of the university approved this study. An informed written consent was obtained from the patients before the study. Refractory hypertension was defined as arterial pressure greater than 140/90 $\mathrm{mmHg}$ despite two or more antihypertensive drugs or hypertension requiring multiple drugs not controlled by pre-transplant antihypertensive drug requirements. ${ }^{8}$ Allograft dysfunction was defined as $>50 \%$ rise of serum creatinine from the baseline. Screening for renal artery stenosis was made by magnetic resonance angiography (MRA) and diagnosis was confirmed by conventional renal angiography. Narrowing greater than $50 \%$ of the luminal diameter of the artery was considered hemodynamically significant. ${ }^{9}$ Age, gender, history of acute rejection, plasma lipid panels, serum creatinine, blood urea nitrogen, serum uric acid, calcium phosphate $\left(\mathrm{CaPO}_{4}\right)$ product, alkaline phosphatase, fasting blood sugar, hemoglobin, and albumin were recorded for each patient. Exclusion criteria were patients with elevated cyclosporine level at presentation and patients with urologic problems at primary hospital evaluation. Maintenance immunosuppressant regimen included cyclosporine, mycophenolate mofetil, and corticosteroids in all patients. Patients with low-density lipoprotein (LDL) cholesterol and uric acid levels of $>100 \mathrm{mg} / \mathrm{dL}$ and $>8 \mathrm{mg} / \mathrm{dL}$ received simvastatin and allopurinol, respectively. All the studied patients, regardless of serum calcium level, were on calcitriol therapy $(0.25 \mu \mathrm{g}$, daily).

Data are presented as mean \pm standard deviation or as median and interquartile range. Statistical analysis was performed with SPSS (v 16; IBM Corp, Armonk, NY) using
Mann-Whitney U test and Fisher's exact test, whenever appropriate. A $P$ value $<0.05$ was considered statistically significant.

\section{Results}

Sixteen kidney transplant recipients, seven men and nine women, were qualified for this study and underwent MRA (Table 1). Renal function deterioration in twelve patients $(75 \%)$ and refractory hypertension in four patients $(25 \%)$ led to clinical suspicion of TRAS. Three of four patients with features of renal artery stenosis on MRA were confirmed to have TRAS by conventional angiography $(18.7 \%$, Table 1). With an estimation of total number of 700 kidney transplantations in our center, incidence of late-onset TRAS was estimated as $\sim 0.4 \%$. Two of the three patients with TRAS had stenosis on the anastomotic site (patients 2 and 3), which showed improvement in symptoms after renal artery percutaneous transluminal angioplasty (PTA). Due to diffuse stenosis in a female patient (patient 1), no interventional procedures were performed to correct the stenosis. Raw data on patients with TRAS are shown in Table 2.

High levels of calcium $(P=0.03)$, phosphorus $(P=0.04), \mathrm{CaPO}_{4}$ product $(P=0.02)$, and LDL cholesterol $(P=0.04)$ were significantly correlated with the risk of TRAS 1 year after renal transplantation. Serum level of uric acid tended to have a significant correlation $(P=0.051)$

Table I Patients' baseline characteristics

\begin{tabular}{|c|c|c|}
\hline & Total $(n=16)$ & TRAS $(n=3)$ \\
\hline Gender (male:female) & $7: 9$ & $2: 1$ \\
\hline Age (year) & $40.3 \pm 14.2$ & $41.0 \pm 3.0$ \\
\hline \multicolumn{3}{|l|}{ Cause of ESRD } \\
\hline CTIN & $4(25 \%)$ & $0(0 \%)$ \\
\hline GN & $4(25 \%)$ & $2(66.6 \%)$ \\
\hline HTN & $5(31.2 \%)$ & $0(0 \%)$ \\
\hline Unknown & $3(18.7 \%)$ & I (33.3\%) \\
\hline \multicolumn{3}{|l|}{ Admission cause } \\
\hline Refractory HTN & $4(25 \%)$ & $2(66.6 \%)$ \\
\hline Creatinine rise & $12(75 \%)$ & I (33.3\%) \\
\hline $\begin{array}{l}\text { Duration of hemodialysis } \\
\text { prior to transplantation } \\
\text { (months) }\end{array}$ & $10(6-19)$ & $7(6-48)$ \\
\hline $\begin{array}{l}\text { Time after transplantation } \\
\text { (months) }\end{array}$ & $36(14.5-57)$ & $48(36-48)$ \\
\hline Systolic BP (mmHg) & 130 (|2|.25-|47.5) & $150(120-160)$ \\
\hline Diastolic BP (mmHg) & $80(80-87.5)$ & $90(80-90)$ \\
\hline
\end{tabular}

Abbreviations: TRAS, transplant renal artery stenosis; ESRD, end stage renal disease; CTIN, chronic tubulointerstitial nephritis; GN, glomerulonephritis; HTN, hypertension; BP, blood pressure; n, number. 
Table 2 Data on patients with transplant renal artery stenosis (TRAS) $(\mathrm{n}=3)$

\begin{tabular}{|c|c|c|c|}
\hline Variable & Patient I & Patient 2 & Patient 3 \\
\hline Age (year) & 38 & 41 & 44 \\
\hline Gender & Female & Male & Male \\
\hline History of acute rejection & Yes & No & No \\
\hline Cause of ESRD & Unknown & $\mathrm{GN}$ & $\mathrm{GN}$ \\
\hline Admission cause & $\begin{array}{l}\text { Creatinine } \\
\text { rise }\end{array}$ & $\begin{array}{l}\text { Refractory } \\
\text { HTN }\end{array}$ & $\begin{array}{l}\text { Refractory } \\
\text { HTN }\end{array}$ \\
\hline $\begin{array}{l}\text { Duration of hemodialysis } \\
\text { before transplantation } \\
\text { (months) }\end{array}$ & 48 & 6 & 7 \\
\hline $\begin{array}{l}\text { Time after transplantation } \\
\text { (months) }\end{array}$ & 48 & 48 & 36 \\
\hline Systolic BP (mmHg) & 120 & 160 & 150 \\
\hline Diastolic BP $(\mathrm{mmHg})$ & 80 & 90 & 90 \\
\hline Creatinine $(\mathrm{mg} / \mathrm{dL})$ & 6 & 2.1 & 1.7 \\
\hline BUN (mg/dL) & 99 & 42 & 40 \\
\hline Hemoglobin (g/dL) & 14 & 10.5 & 10 \\
\hline $\mathrm{LDL}(\mathrm{mg} / \mathrm{dL})$ & 150 & 116 & 104 \\
\hline Triglyceride (mg/dL) & 216 & 181 & 181 \\
\hline Cholesterol (mg/dL) & 177 & 200 & 200 \\
\hline Uric acid (mg/dL) & 10 & 8 & 8.5 \\
\hline Albumin $(g / d L)$ & 3.4 & 4.3 & 4 \\
\hline $\mathrm{HDL}(\mathrm{mg} / \mathrm{dL})$ & 16 & 48 & 48 \\
\hline Alkaline phosphatase (U/L) & 200 & 174 & 180 \\
\hline $\mathrm{FBS}(\mathrm{mg} / \mathrm{dL})$ & 96 & 100 & 95 \\
\hline Calcium (mg/dL) & 9.5 & 9.7 & 10 \\
\hline Phosphorus (mg/dL) & 5 & 4.6 & 5 \\
\hline $\mathrm{CaPO}_{4}$ product $\left(\mathrm{mg}^{2} / \mathrm{dL}^{2}\right)$ & 47.5 & 44.6 & 50 \\
\hline
\end{tabular}

Abbreviations: ESRD, end stage renal disease; GN, glomerulonephritis; HTN, hypertension; BP, blood pressure; BUN, blood urea nitrogen; LDL, low-density lipoprotein; HDL, high-density lipoprotein; FBS, fasting blood sugar.

(Table 3). There were no differences in other risk factors for atherosclerosis including hypertension and obesity $\left(\mathrm{BMI} \geq 30 \mathrm{~kg} / \mathrm{m}^{2}\right)$ between the patients with and without TRAS $(P>0.05)$. None of the patients had diabetes mellitus before the renal transplant. However, four patients in the non-TRAS group had post-transplant diabetes mellitus $(P>0.05)$.

\section{Discussion}

TRAS is the most frequent vascular complication in renal transplantation. ${ }^{2}$ TRAS can occur due to multiple etiologies, but stenosis occurring later after transplantation usually reflects atherosclerotic disease. ${ }^{8,10}$ In this study, we focused on potential risk factors of TRAS. The study revealed that $\mathrm{CaPO}_{4}$ product, $\mathrm{LDL}$ cholesterol, and perhaps uric acid may increase the risk of TRAS development late after renal transplantation. The former, although not investigated in TRAS, has been correlated with an increased risk for allograft loss in kidney transplant recipients as
Table 3 Univariate analysis of recipient variables for transplant renal artery stenosis (TRAS)

\begin{tabular}{|c|c|c|c|}
\hline Variable & $\begin{array}{l}\text { Non-TRAS } \\
\text { group }(n=13)\end{array}$ & $\begin{array}{l}\text { TRAS } \\
\text { group }(n=3)\end{array}$ & $P$ value \\
\hline Age (year) & $43(23.5-52.5)$ & $4 I(38-44)$ & $0.94^{\mathrm{a}}$ \\
\hline Gender (male:female) & $5: 8$ & $2: 1$ & $0.55^{\mathrm{b}}$ \\
\hline $\begin{array}{l}\text { Positive history } \\
\text { of acute rejection }\end{array}$ & $2(15.4 \%)$ & I (33.3\%) & $0.48^{\mathrm{b}}$ \\
\hline Simvastatin intake & $5(38.4 \%)$ & $3(100 \%)$ & $0.20^{\mathrm{b}}$ \\
\hline Allopurinol intake & $3(23 \%)$ & $3(100 \%)$ & $0.03^{\mathrm{b*}}$ \\
\hline Creatinine (mg/dL) & $1.7(1.5-2.1)$ & $2.1(1.7-6)$ & $0.19^{a}$ \\
\hline BUN (mg/dL) & $36(3 \mid-52)$ & $42(40-99)$ & $0.20^{\mathrm{a}}$ \\
\hline Hemoglobin (g/dL) & $10(9.4-10.1)$ & $10.5(10-14)$ & $0.08^{\mathrm{a}}$ \\
\hline $\mathrm{LDL}(\mathrm{mg} / \mathrm{dL})$ & $78(72-102)$ & $116(104-150)$ & $0.04^{a^{*}}$ \\
\hline Triglyceride (mg/dL) & $136(100.5-188.5)$ & $181(181-216)$ & $0.3 \mathrm{I}^{\mathrm{a}}$ \\
\hline Cholesterol (mg/dL) & $157(\mid 34-170)$ & 200 (I77-200) & $0.06^{\mathrm{a}}$ \\
\hline Uric acid (mg/dL) & $6.5(4.8-7.5)$ & $8.5(8-10)$ & $0.05^{\mathrm{a}}$ \\
\hline Albumin (g/dL) & $4(3.7-4.3)$ & $4(3.4-4.3)$ & $0.89^{a}$ \\
\hline $\mathrm{HDL}(\mathrm{mg} / \mathrm{dL})$ & $45(35-50.5)$ & $48(16-48)$ & $0.73^{\mathrm{a}}$ \\
\hline $\begin{array}{l}\text { Alkaline phosphatase } \\
\text { (U/L) }\end{array}$ & $190(134-298)$ & $180(174-200)$ & $0.94^{\mathrm{a}}$ \\
\hline $\mathrm{FBS}(\mathrm{mg} / \mathrm{dL})$ & $100(87.5-150)$ & $96(95-100)$ & $0.63^{\mathrm{a}}$ \\
\hline Calcium (mg/dL) & $9(8.9-9.2)$ & $9.7(9.5-10)$ & $0.03^{a^{*}}$ \\
\hline Phosphorus (mg/dL) & $4(3 . I-4.6)$ & $5(4.6-5)$ & $0.04^{a^{*}}$ \\
\hline $\begin{array}{l}\mathrm{CaPO}_{4} \text { product } \\
\left(\mathrm{mg}^{2} / \mathrm{dL}^{2}\right)\end{array}$ & $36(28.4-42.3)$ & $47.5(44.6-50)$ & $0.02^{\mathrm{a}^{*}}$ \\
\hline
\end{tabular}

Notes: "Statistically significant $(P<0.05)$; ${ }^{M}$ Mann-Whitney $U$ test; ${ }^{\text {b } F i s h e r ' s ~ e x a c t ~ t e s t . ~}$ Abbreviations: BUN, blood urea nitrogen; $L D L$, low-density lipoprotein; HDL, high-density lipoprotein; FBS, fasting blood sugar.

described by Schaeffner et al. ${ }^{11}$ Interestingly, in a study on apolipoprotein E-deficient mice with normal and reduced renal function, Phan and colleagues found that the progression of intimal and medial arterial calcification was reduced after the administration of sevelamer (phosphate binder) with a significant decrease in the serum phosphate and calcium product while the serum total cholesterol remained unchanged. ${ }^{12}$ Research has also shown that in chronic hemodialysis patients, with no clinical evidence of infectious or inflammatory conditions, $\mathrm{CaPO}_{4}$ product was directly related to the C-reactive protein (CRP) concentrations. ${ }^{13}$ An elevated plasma concentration of CRP, in turn, is generally believed to be an indicator of cardiovascular risk both in non-uremic and uremic patients. ${ }^{14}$ We propose that an elevated calcium phosphate product may mean that renal transplant patients are susceptible to TRAS, possibly by induction of inflammation, vascular calcification, and accelerated atherosclerosis. Evidence suggests that the goal level of $\mathrm{CaPO}_{4}$ product should be below $55 \mathrm{mg}^{2} / \mathrm{dL}^{2}$. In other words, there is increased risk for development of calcification and possibly increased risk for lower patient survival if $\mathrm{CaPO}_{4}$ product levels 
exceed $55 \mathrm{mg}^{2} / \mathrm{dL}^{2} .{ }^{15}$ In the present study, although the median $\mathrm{CaPO}_{4}$ product was lower than the recommended level (47.5 vs $55 \mathrm{mg}^{2} / \mathrm{dL}^{2}$ ), high $\mathrm{CaPO}_{4}$ product level was correlated with late-onset TRAS. Therefore, related guidelines should be updated in this regard to define a more appropriate goal level of $\mathrm{CaPO}_{4}$ product in the renal transplant population.

High levels of LDL were also significantly associated with TRAS in our study. Although Scoble et al found no significant difference in LDL levels between non-transplant patients with atherosclerotic renal artery stenosis, and controls, ${ }^{16}$ Ruiz et al found that LDL was higher in stable renal transplant patients with atherosclerotic carotid artery lesions, than in patients without carotid lesions. ${ }^{17}$ Notably, it has been shown that renal transplant recipients had lower activity of serum paraoxanase, which inhibits oxidation of LDL. ${ }^{18}$ On the other hand, it has been shown that increased oxidative stress and final products of lipid peroxidation along with reduced antioxidant status might be observed in patients after renal transplantation, compared with healthy individuals. ${ }^{17,19}$ Hence, it is quite possible that LDL in setting of decreased antioxidant activity may contribute to the accelerated atherosclerosis in renal transplant patients. Nonetheless, the present study did not address the issue of antioxidant capacity among renal transplant patients. The indicated reduced antioxidant capacity in renal transplant patients may provide an environment in which uric acid acts as pro-oxidant contributing to the accelerated atherosclerosis through inducing endothelial dysfunction and inflammation. ${ }^{20}$ Although uric acid in the early stages of the atherosclerotic process is known to act as an antioxidant, it is pro-oxidative under reduced antioxidant status, as well. ${ }^{19}$ This might reinforce the importance of a high level of uric acid as a probable risk factor of TRAS, though this parameter merely tended to correlate with TRAS in the present study.

This study has certain limitations. It was a single-center study with quite a small sample size. Evaluation of the risk factors for renal artery stenosis in kidney transplants is recommended in larger, possibly multi-center populations. The TRAS group comprised only three patients and thus the statistical analysis of data may not be applicable. Therefore, the raw data of each case were also included.

In conclusion, it seems that high $\mathrm{CaPO}_{4}$ product, LDL cholesterol, and perhaps uric acid are correlated with TRAS in living donor renal transplant recipients 1 year after the renal transplantation, suggesting the importance of early detection and tight control of these potential risk factors.
Further prospective studies are needed to define the risk factors of TRAS.

\section{Disclosure}

The authors declare no conflicts of interest in relation to this paper.

\section{References}

1. Ardalan MR, Tarzamni MK, Shoja MM, et al. Black tea improves endothelial function in renal transplant recipients. Transplant Proc. 2007;39:1139-1142.

2. Fervenza FC, Lafayette RA, Alfrey EJ, Petersen J. Renal artery stenosis in kidney transplants. Am J Kidney Dis. 1998;31:142-148.

3. Patel NH, Jindal RM, Wilkin T, et al. Renal arterial stenosis in renal allografts: retrospective study of predisposing factors and outcome after percutaneous transluminal angioplasty. Radiology. 2001;219:663-667.

4. Ardalan MR, Shoja MM, Tubbs RS, Ghabili K. Transplant renal artery stenosis associated with acute cytomegalovirus infection: resolution following ganciclovir administration. Ren Fail. 2009;31: 982-984.

5. Bruno S, Remuzzi G, Ruggenenti P. Transplant renal artery stenosis. J Am Soc Nephrol. 2004;15:134-141.

6. Audard V, Matignon M, Hemery F, et al. Risk factors and long-term outcome of transplant renal artery stenosis in adult recipients after treatment by percutaneous transluminal angioplasty. Am J Transplant. 2006;6:95-99.

7. Becker BN, Odorico JS, BeckerYT, et al. Peripheral vascular disease and renal transplant artery stenosis: a reappraisal of transplant renovascular disease. Clin Transplant. 1999;13:349-355.

8. Pouria S, State OI, Wong W, Hendry BM. CMV infection is associated with transplant renal artery stenosis. QJM. 1998;91:185-189.

9. Fernández-Nájera JE, Beltrán S, Aparicio $\mathrm{M}$, et al. Transplant renal artery stenosis: association with acute vascular rejection. Transplant Proc. 2006;38:2404-2405.

10. Buturovic-Ponikvar J. Renal transplant artery stenosis. Nephrol Dial Transplant. 2003;18:v74-v77.

11. Schaeffner ES, Födinger M, Kramar R, Sunder-Plassmann G, Winkelmayer WC. Prognostic associations of serum calcium, phosphate and calcium phosphate concentration product with outcomes in kidney transplant recipients. Transpl Int. 2007;20:247-255.

12. Phan O, Ivanovski O, Nguyen-Khoa T, et al. Sevelamer prevents uremiaenhanced atherosclerosis progression in apolipoprotein E-deficient mice. Circulation. 2005;112:2875-2882.

13. Movilli E, Feliciani A, Camerini C, et al. A high calcium-phosphate product is associated with high C-reactive protein concentrations in hemodialysis patients. Nephron Clin Pract. 2005;101: c161-c167.

14. Brancaccio D, Tetta C, Gallieni M, Panichi V. Inflammation, CRP, calcium overload and a high calcium-phosphate product: a "liaison dangereuse." Nephrol Dial Transplant. 2002;17:201-203.

15. K/DOQI Clinical Practice Guidelines for Bone Metabolism and Disease in Chronic Kidney Disease. Guideline 6. Serum Calcium and Calcium-Phosphorus Product. Available from: http://www.kidney.org/ professionals/kdoqi/guidelines_bone/guide6.htm. Accessed June 16, 2011.

16. Scoble JE, de Takats D, Ostermann ME, et al. Lipid profiles in patients with atherosclerotic renal artery stenosis. Nephron. 1999;83:117-121.

17. Ruiz MC, Medina A, Moreno JM, et al. Relationship between oxidative stress parameters and atherosclerotic signs in the carotid artery of stable renal transplant patients. Transplant Proc. 2005;37:3796-3798. 
18. Paragh G, Asztalos L, Seres I, et al. Serum paraoxonase activity changes in uremic and kidney-transplanted patients. Nephron. 1999;83: 126-131.

19. Moreno JM, Ruiz MC, Ruiz N, et al. Modulation factors of oxidative status in stable renal transplantation. Transplant Proc. 2005;37: $1428-1430$.
20. Johnson RJ, Kang DH, Feig D, et al. Is there a pathogenetic role for uric acid in hypertension and cardiovascular and renal disease? Hypertension. 2003;41:1183-1190.

\section{Publish your work in this journal}

Vascular Health and Risk Management is an international, peerreviewed journal of therapeutics and risk management, focusing on concise rapid reporting of clinical studies on the processes involved in the maintenance of vascular health; the monitoring, prevention and treatment of vascular disease and its sequelae; and the involvement of metabolic disorders, particularly diabetes. This journal is indexed on PubMed Central and MedLine. The manuscript management system is completely online and includes a very quick and fair peer-review system, which is all easy to use. Visit http://www.dovepress.com/ testimonials.php to read real quotes from published authors.

Submit your manuscript here: http://www.dovepress.com/vascular-health-and-risk-management-journal 